\title{
Make to learn: invention through emulation
}

\author{
Glen Bull ${ }^{1 *}$ (D, Joe Garofalo ${ }^{1}$, Michael Littman², Roger Sherman ${ }^{3}$, Matthew Hoffman ${ }^{3}$, Michael M. Grant ${ }^{4}$ \\ and Alan Grier ${ }^{5}$
}

\author{
* Correspondence: \\ gbull@virginia.edu \\ ${ }^{1}$ Curry School of Education, \\ University of Virginia, P.O. Box \\ 400273, Charlottesville, VA \\ 22904-4273, USA \\ Full list of author information is \\ available at the end of the article
}

\begin{abstract}
The Make to Learn coalition was established to identify effective pedagogical approaches for employing makerspaces for educational innovation in schools. The Make to Learn coalition is anchored by the Make to Learn Laboratory in the Curry School of Education at the University of Virginia and the Laboratory School for Advanced Manufacturing in the Charlottesville City Schools, working in collaboration with the Joseph Henry project at Princeton University, advanced manufacturing programs at Midlands Technical College, and the Smithsonian Institution. This paper describes a key consortium initiative, American Innovations in an Age of Discovery. Participating students use school makerspaces to reconstruct working models of transformational inventions. The reconstruction process is grounded in a method employed by historic inventors, invention through emulation. The benefits of this approach, updated to take advantage of modern technologies, are discussed in the context of maker education.
\end{abstract}

\section{Introduction}

Much of the current school curriculum in the United States is based on a model established by the National Education Association's Committee of Ten at the end of the nineteenth century. This model separates content by subject and grade level and places an emphasis on theoretical knowledge (Hertzberg, 1988). In recent years an increasing emphasis has been placed on science, technology, engineering, and mathematics (STEM) learning. Integrated STEM learning focuses not only on theoretical knowledge but on "what you can do with what you know" in real-world contexts (U.S. Department of Education, 2015) This emphasis has been reflected in the Next Generation Science Standards (NGSS, 2013), which established cross-cutting concepts across multiple domains of science and engineering. The standards integrate the practices of scientists and engineers with the teaching of content. The goal of NGSS is to "allow students to apply the material" (NGSS, 2013, p. 2).

Integrated STEM learning presents challenges. Current science and mathematics teachers were prepared under accreditation and licensure standards that emphasize expertise in an area of specialization. Further, they must cover a broad range of topics in a curriculum that is already filled with existing content. Tom Carroll, director of the U.S. Office of Educational Technology initiative, Preparing Tomorrow's Teachers to Use Technology initiative, once asked, "If we didn't have the schools we have today, would we create the schools we have today?" (Carroll, 2000). While it is certainly the case that if today's schools were being designed from the ground

(c) The Author(s). 2017 Open Access This article is distributed under the terms of the Creative Commons Attribution 4.0 International License (http://creativecommons.org/licenses/by/4.0/), which permits unrestricted use, distribution, and reproduction in any medium, provided you give appropriate credit to the original author(s) and the source, provide a link to the Creative Commons license, and indicate if changes were made. 
up, a different model might be adopted, in practice a well-established system of accreditation and licensure is in place. Any new innovation must be incorporated into the existing system. Consequently, each of the existing STEM subjects are taught in isolation for the most part.

The nineteenth century offers a model for integrated STEM learning. The nineteenth century was an era of technological change unprecedented before or since (Hindle, 1981; Smil, 2005). The United States was transformed from a rural, agricultural nation to a technological leader. Brooke Hindle, past director of the Smithsonian's National Museum of American History, refers to this period as an "American Industrial Revolution." During his time as director of the Museum, Hindle investigated the factors underlying this transformation and summarized his conclusions in Invention and Emulation (Hindle, 1981).

Hindle (1981) noted that mechanical creativity and inventiveness were at the center of these technological advances, facilitated by Americans' familiarity with machinery. Farmers used machines that included seed drills, turpentine and whiskey stills, gristmills and sawmills, and clocks. Mechanics and artisans worked with gears and gear trains, cams, ratchets, escapements, bearings, cylinders, pistons, valves, and petcocks. These mechanisms were the basic building blocks from which the new mechanical devices and inventions were constructed.

\section{Invention through emulation}

Hindle (1981) concluded that the educational methods of the nineteenth century played a crucial role in the process of invention and innovation. A machinist's apprentice learned by copying the best models. A journeyman was expected to use a master work as a starting point of reference and extend it, improving upon the original. This type of emulation led to new inventions like the telegraph, which remixed and combined a number of elements to create new innovations. Hindle described the method by which mechanical knowledge was transferred from one generation to the next as "invention through emulation." Today the term remixing is used to describe a similar process. Almost all contemporary patents involve remixing elements from prior inventions (Strumsky \& Lobo, 2015). This was the case for nineteenth-century inventions and is equally valid for today's inventions.

Mechanical technologies are as important today as in previous eras. A strong manufacturing industry is essential for any nation's economic prosperity (Smil, 2005). The manufacturing value-added chain accounts for one third of all goods and services in the United States (Gold, 2016). Advanced manufacturing technologies are transforming many fields of engineering and associated design processes. Industrial automation is driving increased productivity but requires skilled workers to fill emerging jobs (Boston Consulting Group, 2013; Rattner, 2017). Schools must prepare students for a future that will require skilled workers to meet this need.

The Make to Learn consortium was established to address this need. This paper describes a key consortium initiative, American Innovations in an Age of Discovery. This initiative enables students to reconstruct working models of transformational inventions. The strategy is grounded in instructional methods described by Hindle and updated for a modern technological era. 


\section{Learning through historical reconstruction}

The pedagogical method developed by the Make to Learn consortium is based on an instructional approach implemented by engineering faculty members Michael Littman and David Billington at Princeton University. Their course, Engineering in the Modern World, allows university students to reconstruct great inventions that shaped the world. The transparency and simplicity of these inventions make them unparalleled in their ability to illuminate their revolutionary underlying ideas (Billington \& Billington, 2013).

This historical approach is still used in some modern-day machine tool programs. Traditionally students in a machine tool degree program begin with a slab of metal and a hand tool. They then progress to manually operated electrical lathes and mills. Once they have mastered these tools, they progress to computer-controlled milling machines. This progression enables students to develop a deep understanding of the properties of the tools and materials used in their craft.

\section{Leveraging makerspaces}

Makerspaces now found in many schools present opportunities for educational innovation embodied by this instructional method: invention through emulation. The term "makerspace" refers to a public space that can be used to make and create (Cavalcanti, 2013). A makerspace enables inventors and entrepreneurs to "design and build almost anything."

America has always been a nation of tinkerers, inventors, and entrepreneurs. In recent years, a growing number of Americans have gained access to technologies such as 3D printers, laser cutters, easy-to-use design software, and desktop machine tools. This, in combination with freely available information about how to use, modify, and build upon these technologies and the availability of crowd funding platforms, is enabling more Americans to design and build almost anything. (White House, 2014, para. 1).

Makerspaces in their current form are a relatively recent innovation (Cavalcanti, 2013). However, as Hindle (1981) noted, learning by making has roots that date to the establishment of the United States. Hindle documented the role that emulation and reconstruction of master works played in shaping the nation, tracing its historical precedent through artifacts in the collections of the Smithsonian Institution.

Extension of this pedagogical method by the Make to Learn consortium has been informed by artifacts in the Joseph Henry collection at Princeton University as well as by artifacts in the collections of the Smithsonian Institution. Joseph Henry taught at Princeton before serving as the first secretary of the Smithsonian Institution. The Joseph Henry collection includes the original mechanisms and apparatus that he used in his experimentation with electricity and magnetism and also those he used in his teaching. The Smithsonian's mission is "the increase and diffusion of knowledge." Reconstruction of inventions in the Smithsonian's collections advances this mission. Artifacts from the Smithsonian's collections and from the Joseph Henry collection at Princeton are the basis for historical reconstructions in the Make to Learn initiative, American Innovations in an Age of Discovery.

The Make to Learn Laboratory in the Curry School of Education at the University of Virginia was established to adapt and extend this method to K-12 schools. A central focus of this effort involves development of Make to Learn Invention Kits that enable students to reconstruct nineteenth-century transformational inventions in school 
makerspaces. Prototypes of historical reconstructions are developed in the Make to Learn Laboratory and field tested in the Laboratory School for Advanced Manufacturing (Lab School). The first iteration of a prototype invention kit is initially implemented in the Lab School classes and then revised based on feedback from teachers and students. (Bull \& Garofalo, 2015; Bull, Haj-Hariri, Atkins \& Moran, 2015).

The Lab School was established to support this method of historical reconstruction and extend it to K-12 schools. The Lab School is a middle school jointly established by the University of Virginia and the Charlottesville City Schools (Bull, Chiu, Berry, \& Lipson, 2013). Members of the core design team bring different perspectives and capabilities to the design process. (See overview of relationships in Fig. 1.) The Smithsonian Institution's mission incorporates strategies for making its collections of transformative inventions and related artifacts more accessible to the broader educational community, and 3D digitization offers a potential way of bringing these collections to schools with makerspaces.

Faculty members at Princeton University are pursuing a related goal of making the technologies that are the foundation of modern civilization more accessible to nontechnical citizens. One mission of Midlands Technical College is focused on workforce development, including facilitation of connections between the interests of K-12 students and potential careers in technical fields. The advanced manufacturing program at Midlands translates mature educational products developed by the Make to Learn consortium into formats that can be fabricated using manufacturing technologies such as injection molding.

\section{Make to learn invention kits}

Among other accomplishments, Joseph Henry was the foremost American scientist in the area of electricity and magnetism in the nineteenth century. He developed an electric motor that was the precursor of the first patented electrical device in the United States, the Davenport rotary motor (U.S. Patent No. 132, 1837). While Davenport was likely unaware of Henry's motor, Davenport purchased an electromagnet designed by Henry and deconstructed it to learn the basic principles of electricity and magnetism

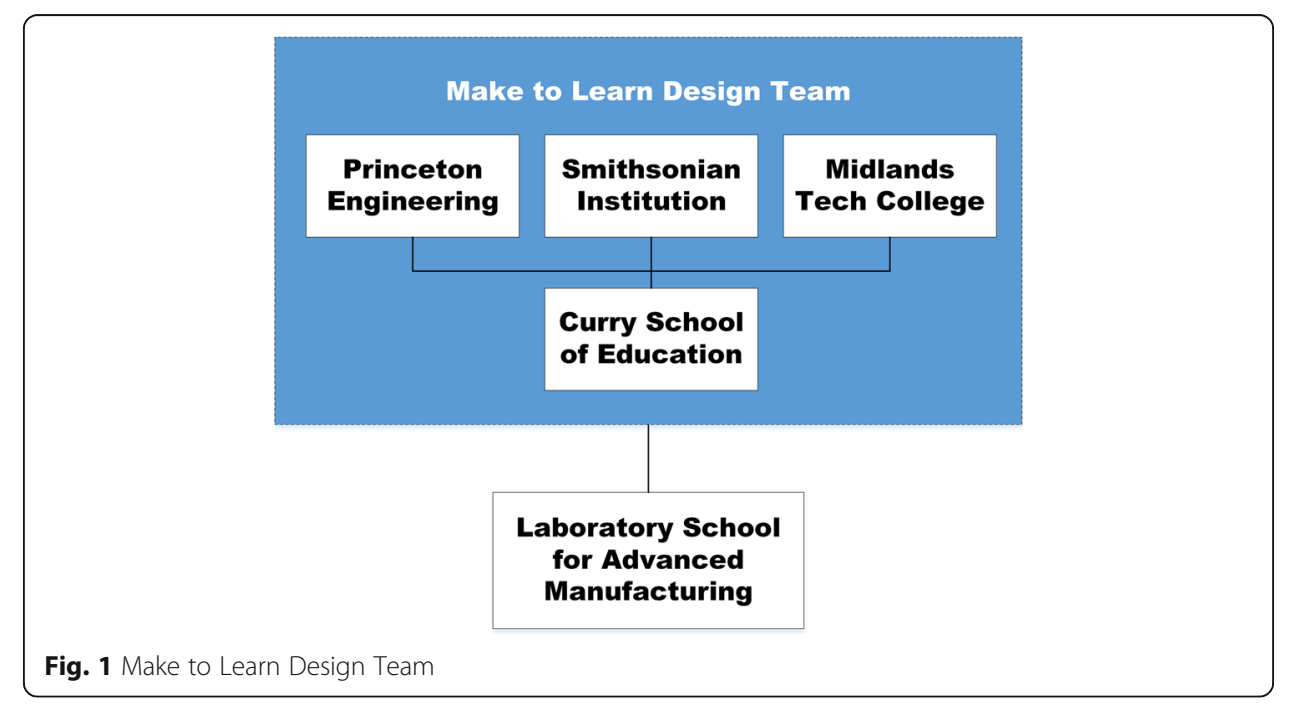


that allowed him to develop his own motor. Henry also developed a proof-of-concept telegraph system that contributed to Samuel Morse's development of the first widely adopted commercial telegraph system and encouraged Alexander Graham Bell in his development of the telephone system.

A series of scientific discoveries led to invention of three great electromagnetic networks in the nineteenth century: the telegraph network, the telephone network, and the electrical power grid. These innovative networks transformed our society. Joseph Henry's work in the field of electromagnetism contributed to development of all three networks. These networks anchor the initial sequence in the American Innovations in an Age of Discovery initiative (Table 1).

Make to Learn Invention Kits introduce students to these seminal electromagnetic networks:

1. Telegraph (including a telegraph key, telegraph relay, and telegraph sounder).

2. Telephone (including a microphone, amplifier, and speaker).

3. Power Grid (including a generator and a sequence of motors).

A series of related tools and instruments have also been developed to support the Invention Kits, including a Solenoid Winder Kit, a Magnetic Pole Detection Invention Kit, and a Mechanical Waveform Generator Invention Kit.

A key goal of Make to Learn historic reconstruction Invention Kits is to present a unified view of these systems and the way in which they provided the foundation for today's modern systems. The nineteenth-century systems were electromechanical. They paved the way for the age of electronics in the twentieth century, which in turn, led to invention of computing systems and the internet (Table 2).

Bell Telephone purchased the rights to the vacuum tube from Lee de Forest and used it to create an electronic amplifier that made the first coast-to-coast phone call possible. To mark the occasion, Alexander Graham Bell placed the first transcontinental call from New York to Thomas Watson in San Francisco in 1915 (McMaster, 2002).

The electronic amplifier made commercial radio feasible. Station KDKA transmitted the first commercial radio broadcast in 1920, ushering in an age of electronics. A new generation of inventors gained experience with electronics through construction of crystal radios. The vacuum tube, and its successor, the transistor, made the electronic computer feasible and led to invention of solid state integrated circuits. The internet became the great twentieth-century network, linking computer systems together to amplify their capabilities.

Historic Invention Kits enable students to reconstruct working models of inventions associated with early electric motors, the telegraph network, and the telephone network. The goal is to enable students to understand the science and engineering

Table 1 Electromagnetic Networks

\begin{tabular}{llll}
\hline Network & Origin & Intermediate & End Point \\
\hline Telegraph Network & Telegraph Key & Relay & Telegraph Sounder \\
Telephone Network & Microphone & Amplifier & Speaker \\
Power Grid & Generator & Transformer & Motors and Lights \\
\hline
\end{tabular}


Table 2 Eras of Innovation

\begin{tabular}{lll}
\hline & Era & Engineering Discipline \\
\hline $1800-1840$ & Age of Discovery & Basic Research \\
$1840-1920$ & Electro-mechanical Age & Mechanical Engineering \\
$1920-1960$ & Electronic Age & Electrical Engineering \\
$1960-2000$ & Computer Age & Computer Science \\
$2000-$ & Age of Making & Mechatronics \\
\hline
\end{tabular}

principles underlying these transformational inventions and the social and economic effects that resulted. Parallel Contemporary Invention Kits aligned with their historic counterparts are planned (Table 3). These modern-day extensions will provide context for understanding the way in which historic inventions laid the foundation for today's modern technologies. The technology introduced remains vital to modern life: in the form of signals sent along electrical wires, electric motors, solenoid devices, automated control systems, and electronic systems.

\section{Make to learn pedagogy}

A Make to Learn pedagogy incorporating the strategy of emulation has evolved over the course of developing and piloting Invention Kits.

\section{Simple to complex}

The telegraph was the first widespread commercial use of electricity. The telegraph system also was an incubator that enabled a generation of inventors to learn about electricity and magnetism. The telegraph evolved in complexity as it matured. For example, technology was developed to allow more than one message to be simultaneously sent down a single telegraph wire. (This capability is known as "multiplexing.") Bell's efforts to create a "harmonic telegraph" that could transmit multiplexed messages through tones contributed to development of the telephone system. Edison was a telegrapher and earned his first fortune by inventing a stock ticker that telegraphically communicated and recorded stock prices. This invention enabled him to establish the Edison research laboratory and contributed to development of an electrical power network used to light homes and businesses in lower Manhattan.

In each instance, simple systems developed into more complex ones as the technology matured. The same principle of simple to complex also guides development of Make to Learn Invention Kits. Reverse engineering is a common engineering process that entails analysis of an existing mechanism to reveal its underlying principles. By this

Table 3 Historical Inventions and Contemporary Counterparts

\begin{tabular}{lll}
\hline Invention Kit & Historical Example & Contemporary Example \\
\hline A. Telegraph Network & Electromechanical Relay & Motor Control (H-Bridge) \\
B. Telephone Network & Vacuum Tube Amplifier & Operational Amplifier \\
C. Electric Motor & Davenport Rotary Motor & Stepper Motor/Servo Motor
\end{tabular}

The planned sequence of contemporary inventions - (A) the Relay/Motor Control Sequence, (B) the Electronic Amplifier Sequence, and $(C)$ the Electric Motor Sequence - are at the heart of industrial automation. A 3D printer consists of microcontrollers, amplifiers, and stepper motors. An understanding of the science and engineering principles that underlie early inventions provides scaffolding for understanding the modern technologies that followed 
means, foundational concepts can be identified that can be introduced through relatively simple designs, which provide scaffolding for the more complex ones that follow (Reigeluth, 1999; Van Merrienboer, Kirschner, \& Kester, 2003). The Make to Learn design team used this method to develop sequences of Invention Kits (Fig. 2):

1. The Solenoid Invention Kit provides scaffolding for construction of a contemporary linear motor.

2. The Linear Motor Invention Kit provides scaffolding for reconstruction of the Charles Page Solenoid Motor.

3. The Charles Page Solenoid Motor Invention Kit, in turn, provides scaffolding for reconstruction of original Davenport rotary motor.

4. The Davenport Rotory Motor Invention Kit provides an introduction to commutators, the mechanism that allowed the first patented electric motor in the United States to achieve continuous rotary motion.

The Simple to Complex principle of the Make to Learn pedagogy is grounded in elaboration theory (Reigeluth, 1999) for sequencing of activities. A specific, narrow example can fix ideas. This can then be used to introduce broader generalizations. Elaboration enlarges schemata in order to assimilate and accommodate new information (Driscoll, 2004).

This Simple to Complex sequencing also informs two other guiding fundamentals. First, this sequencing helps to size (or chunk) the historical innovations and learning activities appropriately for improved cognition (as in Driscoll, 2004; Tulving \& Craik, 2000). By focusing on the simplest machines and innovations, complexity is added as new innovations are added. Second, the sequencing supports an emergent learning principle of making science visible. Chronologically, the innovations increase in complexity. Thus, by starting with the historical innovations, the simplicity of science and engineering are more accessible to students.

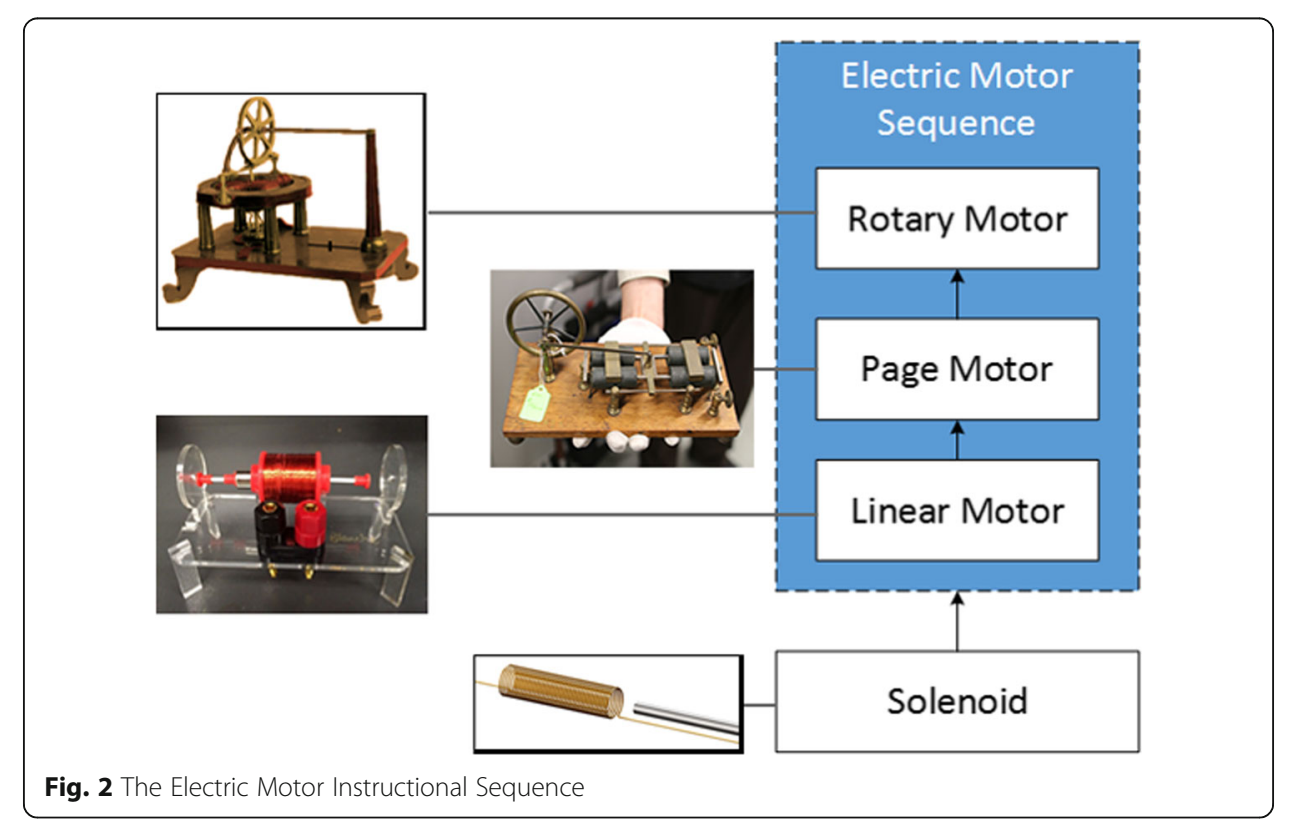




\section{Project based learning}

Make to Learn instructional methods are grounded in Project Based Learning (PBL). PBL is a teaching method in which students gain knowledge and skills by working for an extended period of time to investigate and respond to an authentic, engaging and complex question, problem, or challenge (Mergendoller, Markham, Ravitz, \& Larmer, 2006).

Each Make to Learn Invention Kit is composed of a series of projects that allow students to acquire the skills and knowledge that lead to construction of a working model of the reconstructed invention. The goal for the students is not to create an exact physical replica, but to reinterpret and reinvent the device using modern manufacturing technologies. For example, Fig. 3 depicts the patent model of the Charles Page electromagnetic engine in the Smithsonian's National Museum of American History Electricity Collection.

The CAD file for a reconstruction of the Charles Page motor is depicted in Fig. 4. There are obvious differences. The reconstruction has two solenoids rather than four. It is constructed of plastic rather than wood. However, the operational principles that underlie its functions are the same. The reconstruction is designed to make these principles accessible through demonstration of the simplest possible form of a working model.

The Make to Learn program models PBL inquiry methods. PBL affords authentic learning tasks grounded in self-direction of learners (Grant, 2011). It emphasizes a driving question that students pursue to produce artifacts as representations of learning (Blumenfeld et al., 1991; Grant, 2011; Krajcik et al., 1994; Marx, Blumenfeld, Krajcik, \& Soloway, 1997). Problems generated through Invention Kits advance learning goals that meet national and state standards, incorporate collaboration, and integrate technology tools (as recommended by Krajcik \& Shin, 2014). The presidents and leaders of the national teacher educator STEM associations have served on the Make to Learn advisory board to facilitate this alignment. These include the Association of Science Teacher Educators (ASTE), the Society for Technology and Teacher Education (SITE), the International Technology and Engineering Education Associations (ITEEA), and the Association of Mathematics Teacher Educators (AMTE).

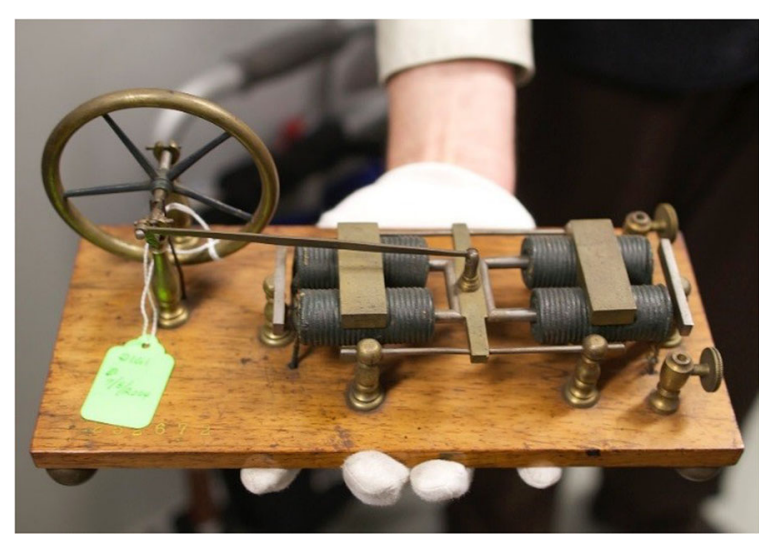

Fig. 3 Hal Wallace, curator of the Smithsonian's Electricity Collections, displays Charles Page "electromagnetic engine" patented in 1854 


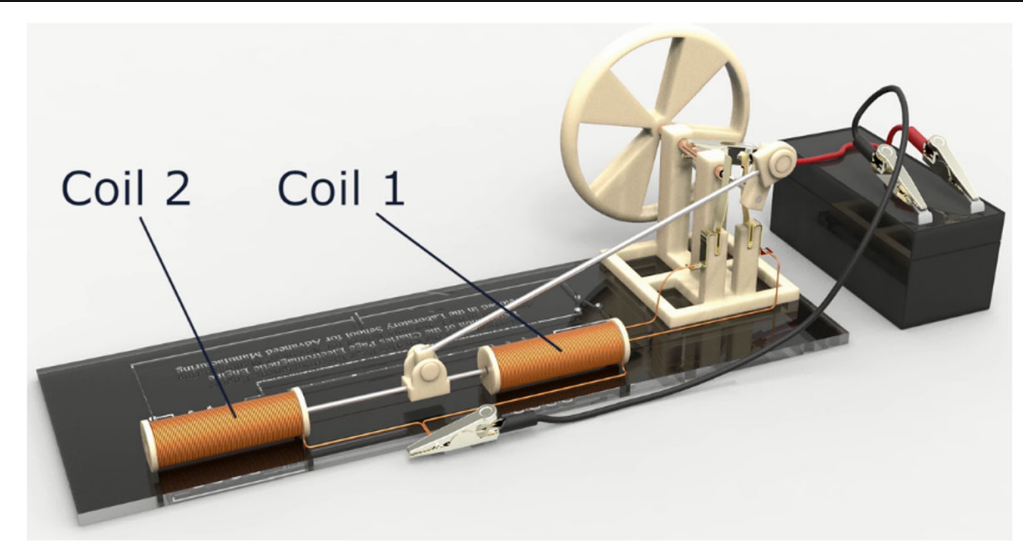

Fig. 4 Reconstruction of the Charles Page Motor

Comprehensive reviews of research have found that a PBL approach enhances the quality of student learning compared with other instructional approaches (Holm, 2011; Thomas, 2000). Compared to students in traditional lecture-based settings, researchers report that PBL students in K-12 settings demonstrate increased positive attitudes toward learning (Morrison, Mcduffie, \& French, 2014), are more self-directed (Deur \& Murray-Harvey, 2005), and have greater learning gains in content knowledge assessment (Boaler, 2002; Holm, 2011).

\section{Contextualized learning}

Situated learning theory acknowledges that what people learn is intimately connected with the context in which they learn it (Brown, Collins, \& Duguid, 1989). The original inventors attempted to solve a specific problem by bringing to bear the requisite disciplines required to address the problem. For example, Morse faced the problem of transmitting the telegraph signal over an extended distance. The methods employed for shorter distances did not suffice for longer telegraph runs. Morse stated that he used Ohm's Law to analyze this problem and develop a solution (Morse, 1855, p. 43). Morse and his associate Leonard Gale conducted tests over 160 miles of wire. He used the data collected to develop a plot of the drop in current as the resistance, in the form of a longer wire, increased. The analytical interpretation concluding that a long-line telegraph was possible was published in the American Journal of Science (Morse, 1845). Morse's solution to the problem consisted of a telegraph relay that could replicate and propagate the signal, thereby making transmission over longer distances practical. While Morse did not have necessary scientific knowledge to develop all of the elements of the telegraph system, he was able to rely on others such as Leonard Gale, Alfred Vail, and Joseph Henry. Development of a commercial telegraph required a team of collaborators working together.

An understanding of the new knowledge of electricity developed by Ampere and Oersted and of electromagnetism by Sturgeon and Henry was a precondition for the telegraph and, consequently, it has also been labeled the first science-based invention (Hindle, 1981, p. 105). Morse applied this knowledge in the context of a specific problem that he was attempting to solve. Today's entrepreneurs often adopt a similar 
approach. Strictly speaking, it should be noted that other inventions prior to the telegraph, such as Galileo's design for a pendulum clock, were grounded in scientific knowledge. However, the telegraph system gave rise to a number of other related industries and inventions and, thus, served as a catalyst for design of electromagnetic inventions grounded in scientific knowledge.

In a similar fashion, Make to Learn pedagogy contextualizes math and science content by providing purpose for the knowledge and skills. For example, students constructing solenoid-based actuators derive Ampere's Law in the course of designing more effective mechanisms (Corum \& Garofalo, in press). To both contextualize content knowledge and generalize it such that it can be used in multiple disciplines, Asghar, Ellington, Rice, Johnson, and Prime (2012) recommended against schools and curricula treating "each STEM discipline as a silo" (p. 86). Invention Kits provide a context for integration of STEM concepts-an approach that can promote authentic interdisciplinary problem solving.

\section{Problem solving and design thinking}

Make to Learn Invention Kits are designed to encourage students to solve interdisciplinary problems. Interdisciplinary problems are often ill-structured. Problems of this kind typically have more than one possible solution and more than one path to a solution (Belland, 2013; Cross, 2000; Jonassen, 1997). In addition, ill-structured problems require learners to bring multiple domains of learning together to propose a solution in order to make knowledge generalizable and flexible across different problems (Hmelo-Silver, 2004). A PBL driving question can situate a problem and motivate learners toward the self-directed learning required to propose a solution/learning artifact (Hmelo-Silver, 2004; Jonassen, 1997).

Invention Kits also provide a context for design thinking. Design thinking as part of engineering design asks students to apply knowledge to develop a prototype that solves a problem. (Johansson-sköldberg \& Woodilla, 2013). These activities reflect an authentic application of engineering design through evaluation, review, and revision of a problem solution (Cross, 2000) and learning through original making (Martin, 2015).

\section{Remixing and emulation}

Remixing is a modern term for the type of nineteenth-century invention through emulation described by Hindle (1981). Strumsky and Lobo (2015) found that remixing of elements to create new inventions is as common today as it was in the nineteenth century. Their analysis of patent data confirmed that new inventions typically recombine elements from prior innovations.

Make to Learn Invention Kits are designed to facilitate acquisition of foundational science principles and related engineering applications and to encourage students to remix these basic elements to create their own innovations using modern technologies. With this goal in mind, the question of how best to facilitate this objective arises.

Flath, Friesike, Wirth, and Thiesse (2017) investigated remixing on Thingiverse, a popular site for sharing $3 \mathrm{D}$ printer files. They concluded that although remixing is pervasive across fields as disparate as music and life sciences, lack of scholarly knowledge about the process stands in sharp contrast to the evident potential. Encouraging 
remixing in schools (see e.g., Griffin, Kaplan \& Burke, 2012) will require an understanding of the factors that facilitate it. Some of the elements that may encourage successful reconstruction and remixing of inventions include (a) website resources, (b) hardware, (c) software, and (d) intellectual property rights. These same elements are relevant to remixing of components of reference designs provided in Make to Learn Invention Kits.

\section{Website resources}

Resources for historical reconstruction Invention Kits include three-dimensional scans of artifacts in the Smithsonian collections hosted on the Smithsonian X 3D website (https://3d.si.edu/). A 3D browsing tool allows students to examine and measure the artifacts. Other resources include animations of mechanisms, 3D printer files, unit plans, project worksheets, and assessment items.

Provision of resources in an editable format facilitates remixing. An ".stl" 3D printer file, the most common file format for 3D printing, cannot easily be edited. Fusion 360 and Solidworks files are two editable file formats that are currently being provided as resources that accompany Invention Kits. Discovery plays an important role in facilitating remixing; the structure of a website can facilitate or inhibit discovery.

\section{Hardware}

Development of each Invention Kit begins with a reference design. In engineering, a reference design is a working model with associated specifications intended for others to copy. Based on experience with implementation of Make to Learn Invention Kits, we identified the following criteria for developing reference designs:

1. Designs should be straightforward to fabricate and assemble.

2. Designs should be robust and reliable to operate.

3. Designs should illuminate underlying concepts related to their operation.

4. Designs should provide strong connections to their historical antecedents.

5. Each design should build naturally on prior content to create a logical progression of inventions.

The components of Make to Learn Invention Kits are standardized to be interchangeable whenever possible. For example, the solenoid bobbin is standardized for use with a magnet that is $3 / 8$ in. in diameter. This strategy allows the same component to be used in the linear motor and the speaker, among other kits. A pegboard mounting platform is standardized on Lego spacing, so that Make to Learn Invention Kit components can be combined and intermixed with Lego parts. In the future development of standardized connectors (pivoting arms, gears, levers, etc.) to create motion would also extend the mechanical vocabulary for constructing and combining elements from several kits to create new inventions.

This approach follows in the footsteps of many other construction systems that preceded Make to Learn kits, such as Meccano Sets, Tinker Toys, and similar sets. A 1922 doctoral dissertation at Columbia University identified more than 40 systems developed in imitation of the original Meccano ("Make and Know") set. The study found that 
projects that combined both mechanical and electrical components, such as a working model of a crane that could move and lift objects, were the most engaging (Meister, 1922).

\section{Software}

Most modern-day mechanisms incorporate a microcontroller and accompanying software. There are a number of models that may suggest potential directions for remixing software components. The MIT Scratch website (https://scratch.mit.edu) is an example of an educational site that encourages students to remix code developed by others to create new programs. This same method of invention through emulation by remixing code elements is commonly employed in university computer science programs. Remixing that draws upon libraries of code elements is common practice in industry as well. Make to Learn Invention Kits provide sample software that can be used with microcontrollers such as the Arduino to control Make to Learn mechanisms.

\section{Intellectual property}

Open source licensing that allows and encourages remixing under specified conditions (i.e., remixing with attribution supported) is a critical factor that affects remixing. Make to Learn Invention Kits are provided in an open source format that encourages noncommercial remixing with attribution.

\section{An illustrative remixed design}

The referent design for the Relay Invention Kit shown in Fig. 5 was developed through a series of design meetings. The design team includes perspectives from multiple disciplines that include science, engineering, mathematics, historians, and pedagogical experts. The design represents the final variant of several dozen designs developed and piloted in schools over a period of several months.

A key decision made by the design team involved constructing the design as two separate components so students could more easily separate the functions of the primary

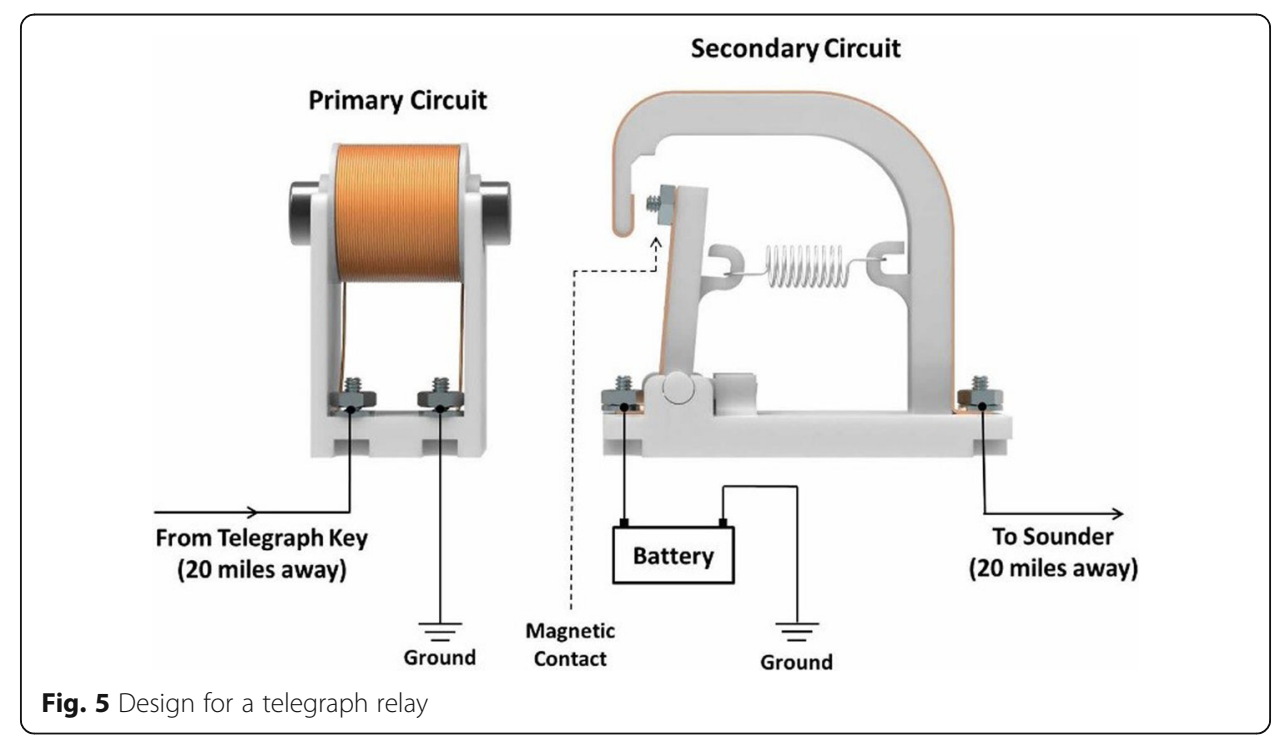


circuit of a relay from the operation of a secondary circuit. This decision illuminates the fact that the primary circuit is essentially an electromagnet, while the secondary circuit is a normally open switch.

The electrical connections for these two functions are combined in today's commercial relays. That factor, combined with abstract symbols used as labels for each relay contact, make the functions of a relay difficult to understand when commercial relays are used. The Make to Learn reference design can be contrasted with a typical nineteenth-century relay from the Smithsonian collections and its modernday counterpart (Fig. 6).

Today relays are often used to allow computers to control physical objects such as solenoid actuators and electrical motors (Fig. 7). This topic is the subject of the Midland Technical College Motor Controls course. The Make to Learn Relay Invention Kit, therefore, proved be useful in technical college courses as well as in K-12 schools.

There is nothing to see in a solid-state relay. It is just a solid block of material. Cutting it in half does not reveal anything about its function or mode of operation. Therefore, the underlying principles remain opaque and somewhat abstract for many students. Once a mechanical telegraph relay has been reconstructed and understood, it can be used to control the reconstructed linear motor. Because the functions of the electromechanical relays are more visible and can be observed, they allow students to develop an understanding of the science underlying relays, their historic context, and their use in contemporary applications (Fig. 8).

Once students understand the function of an electromechanical relay - using a small electrical current in a primary circuit to control a larger current in a secondary circuit - they can apply this knowledge using contemporary solid state relays.

\section{Conclusion}

Engineering provides opportunities for students to deepen their understanding of science by applying knowledge in context. Another NSF-supported project (Katehi, Pearson, \& Feder, 2009) found that theoretical knowledge alone was insufficient to ensure that students could apply that knowledge in real-world tasks. Constructing and testing real products can close the gap between theoretical and applied knowledge. Some of the lessons learned in the process of developing Make to Learn Invention Kits include the following.

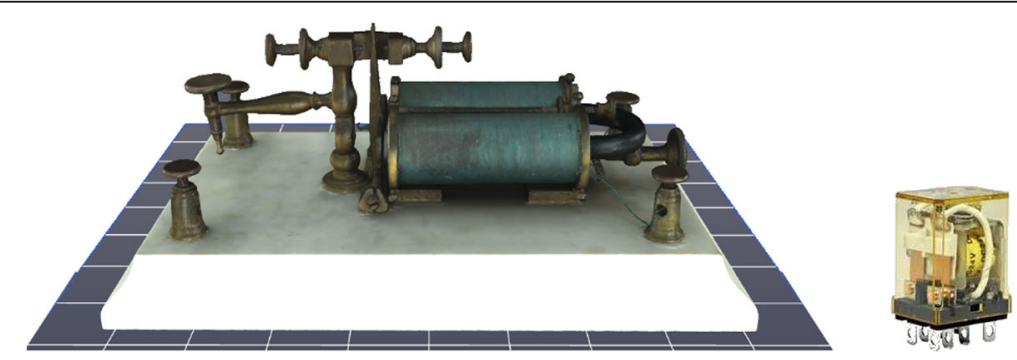

Fig. 6 Scanned image (left) of a nineteenth-century telegraph relay in the Smithsonian X 3D browser and its modern-day equivalent 


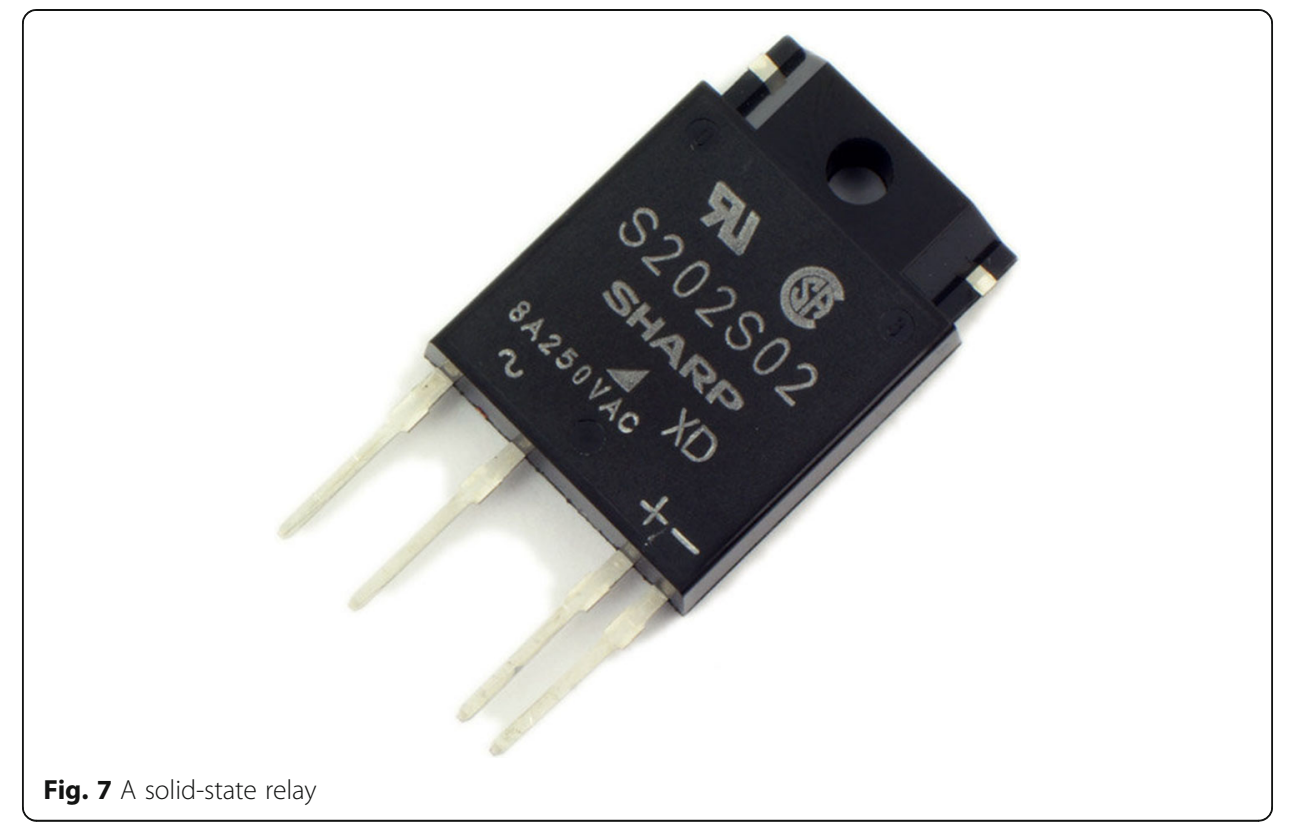

\section{Innovation is intentional}

The connections among invention systems of the nineteenth century represent complex patterns. Much of the popular advice for students encourages them to be creative and to "think outside of the box." This oversimplifies the process of invention, at least for innovations of any complexity. In fact, extensive planning, thought, and skill were required to successfully implement the nineteenth-century inventions studied thus far.

Similarly, extensive planning and hands-on investigation were required to unravel the patterns underlying nineteenth-century systems and connect them to twenty-firstcentury systems. Hindle (1988, p. X) expressed a conviction that "artifacts, drawings, and photographs provide an entry to the understanding of technology not attainable from the written record alone" Successfully unraveling nineteenth-century patterns required hands-on experimentation complemented by theoretical study. In that regard, development of effective pedagogies involving historical reconstructions required development of an intentional system in the same manner that development of the original inventions themselves required a systematic approach that involved both applied and theoretical knowledge.

\section{Innovation is iterative}

Development of each of the nineteenth-century systems involved development of an initial workable instance that served as a proof-of-concept. A series of iterations often extending over a period of years was required to optimize the system.

Development of Make to Learn Invention Kits required a similar sequence of iterations. The initial prototype for a historical reconstruction often required extensive expertise, skill, and class time to implement. Successive iterations increased the percentage of students who could successfully implement the Invention Kit and reduced the amount of class time required for implementation. 


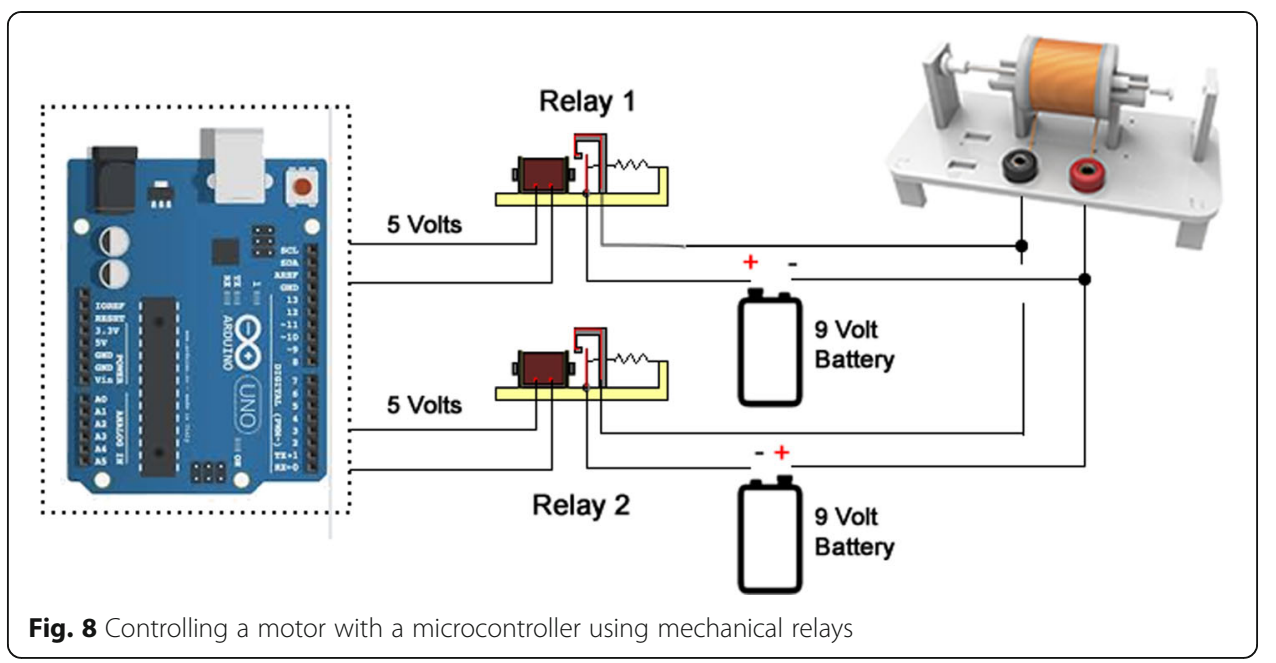

\section{Institutional alignment is crucial}

A broad coalition of collaborators was required to develop effective Invention Kits. The expertise represented included an understanding of the history of science, an applied knowledge of electromechanical systems, an understanding of relevant content knowledge and related educational standards, and many other fields of expertise. This expertise also included the ability to move from an initial prototype of an Invention Kit to manufactured kits, thus encompassing the entire design cycle. No single collaborative partner had the requisite expertise. In order to successfully sustain a long-term coalition, alignment of institutional goals is essential. If there is not an authentic connection with institutional missions, the collaboration will not be sustainable.

\section{Engineering is essential}

Engineering serves as a natural hub that lies at the intersection of science, mathematics, and technology. The inventors of nineteenth-century systems needed science, mathematics, and technology to successfully implement their innovations. They did not learn science or mathematics in isolation, however. They identified requisite knowledge at the time that was required to solve a problem and then applied it in the context of the invention.

The ITEEA, which has been a collaborative partner in development of Make to Learn Invention Kits, highlights this point in its definition of "integrative STEM," noting that it entails pedagogical practices that intentionally teach science and mathematics in the context of applied engineering practice (Wells \& Ernst, 2015). In that regard, this pedagogy does not differ from the 19th-century practices of the original inventors.

Make to Learn Invention Kits connect foundational inventions first developed in the nineteenth century to their modern-day applications. Students, for example, are able to see how Thomas Davenport's rotary motor patented in 1837 provided the foundation for today's stepper motors. As students develop an understanding of basic building blocks, they gain an ability to recombine Invention Kit components in an infinite number of ways as they design and construct their own inventions. 
Examination of transformational systems such as the telegraph network, the telephone network, and the electrical power grid reveals that although these inventions are associated with a single individual such as Samuel Morse, Alexander Graham Bell, or Thomas Edison, in reality many others contributed to development of these innovative systems. Hindle (1981), for example, has documented the way in which the science underlying the prototype telegraph that Joseph Henry developed at Princeton contributed to Morse's practical application for commercial use. Contributions by other individuals such as Morse's collaborator Alfred Vail and Morse's colleagues at New York University are also well documented. The telegraph, in turn, served as an incubator that made invention of the telephone network possible. In a real sense, the telephone network was a remixing of the telegraph network that preceded it. Edison's early inventions such as the stock ticker were made possible by the telegraph system and, in turn, were remixed into the electrical network that he developed.

In a similar manner, the pedagogical methods and applications incorporated into Make to Learn Invention Kits draw upon knowledge that spans many disparate disciplines distributed across the Make to Learn network of collaborators. Collaborators include industrial partners such as engineers at Sag Harbor Industries (founded by Thomas Edison's son), work piloted at Princeton that rests upon instructional methods and apparatus developed by Joseph Henry, practical applications of these concepts in advanced manufacturing programs at Midlands Technical College, resources provided by curators and educational specialists at the Smithsonian Institution, and many others. Collaborators in the Make to Learn network are, in a sense, emulating methods employed by historic inventors and remixing them for educational innovation in the contemporary era.

\section{Acknowledgements}

This material is based on work supported by National Science Foundation Grants No. 1030865 The FabLab Classroom and No. 15113018 American Innovations in an Age of Discovery. We also gratefully acknowledge the input and perspectives of many individuals who have contributed to the final version of this document, and in particular, theoretical perspectives contributed by Michael Spector. Any opinions, findings, and conclusions or recommendations expressed in this manuscript are those of the authors.

Authors' contributions

The contributions of authors are as follows: GB is the principal investigator for this work. JG and ML are co-principal investigators. RS is an Associate Curator in the Division of Medicine and Science of the Smithsonian National Museum of American History. MH is an educational specialist in the Division of Education and Outreach of the Smithsonian National Museum of American History. RS and MH contributed perspectives related to the history of technology and science. MM. Grant is the director of educational technology at the University of South Carolina and contributed perspectives related to the learning sciences. AG is director of the Machine Tool program and the Mechatronic program at Midlands Technical College and contributed perspectives related to manufacturing technology. All authors read and approved the final manuscript.

Competing interests

The authors declare that they have no competing interests.

\section{Publisher's Note}

Springer Nature remains neutral with regard to jurisdictional claims in published maps and institutional affiliations.

\section{Author details}

${ }^{1}$ Curry School of Education, University of Virginia, P.O. Box 400273, Charlottesville, VA 22904-4273, USA. ${ }^{2}$ Princeton University, Princeton, New Jersey, USA. ${ }^{3}$ National Museum of American History, Smithsonian Institution, Washington, DC, USA. ${ }^{4}$ College of Education, University of South Carolina, Columbia, South Carolina, USA. ${ }^{5}$ Midlands Technical College, Columbia, South Carolina, USA. 
Received: 19 November 2017 Accepted: 20 November 2017

Published online: 06 December 2017

\section{References}

A Asghar, R Ellington, E Rice, F Johnson, GM Prime, Supporting STEM education in secondary science contexts. Interdisciplinary Journal of Problem-Based Learning 6(2) (2012). doi: 10.7771/1541-5015.1349

BR Belland, in Learning, Problem Solving, and Mindtools: Essays in Honor of David H. Jonassen, ed. by J M Spector, B Lockee, S E Smaldino, M C Herring. Mindtools for argumentation, and their role in promoting ill-structured problem solving (Routledge, New York, NY, 2013), pp. 229-246

DP Billington, DP Billington Jr, Power, Speed, and Form: Engineers and the Making of the Twentieth Century (Princeton University Press, Princeton, NJ, 2013)

P Blumenfeld, E Soloway, R Marx, J Krajcik, M Guzdial, A Palincsar, Motivating project-based learning: Sustaining the doing, supporting the learning. Educ. Psychol. 26(3/4), 369-398 (1991). doi: 10.1207/s15326985ep2603\&4_8

J Boaler, Learning from teaching: Exploring the relationship between reform curriculum and equity. J. Res. Math. Educ. 33(4), 239-258 (2002)

JS Brown, A Collins, P Duguid, Situated cognition and the culture of learning. Educ. Res. 18(1), 32-42 (1989)

G Bull, JL Chiu, RQ Berry, H Lipson, in Handbook of Research on Educational Communications and Technology, 4th edn. ed. by J Spector, M Merrill, J Elen, M J Bishop. Advancing children's engineering through desktop manufacturing (Springer-Verlag, New York, NY, 2013), pp. 675-688

G Bull, J Garofalo, in The SAGE Encyclopedia of Educational Technology, ed. by J M Spector. Technologies to support engineering education (SAGE Publications, Thousand Oaks, CA, 2015), pp. 740-743

Bull, G., Haj-Hariri, H., Atkins, R., \& Moran, P. (2015). An educational framework for digital manufacturing in schools. Journal of 3D Printing and Additive Manufacturing, 2, 42-49.

TG Carroll, If we didn't have the schools we have today, would we create the schools we have today? Contemporary Issues in Technology and Teacher Education 1(1), 117-140 (2000)

G Cavalcanti, in Make Magazine. Is it a hackerspace, makerspace, techshop, or fablab? (2013) Retrieved from https://makezine.com/2013/05/22/the-difference-between-hackerspaces-makerspaces-techshops-and-fablabs/

Corum, K., \& Garofalo, J. (in press). Analyzing 3D-Printed Artifacts to Develop Mathematical Modeling Strategies. Technology and Engineering Teacher.

N Cross, Engineering design methods, 4th edn. (John Wiley \& Sons Ltd., Chichester, ENG, 2000)

MP Driscoll, Psychology of Learning for Instruction, 3rd edn. (Allyn \& Bacon, Needham Heights, MA, 2004)

CM Flath, S Friesike, M Wirth, F Thiesse, Copy, transform, combine: Exploring the remix as a form of innovation. J. Inf. Technol. (2017). doi: 10.1057/s41265-017-0043-9

S Gold, Manufacturing's economic impact. Industry Week. (2016, February 17) Retrieved from http://www.industryweek. com/global-economy/manufacturings-economic-impact-so-much-bigger-we-think

MM Grant, Learning, beliefs, and products: Students' perspectives with project-based learning. Interdisciplinary Journal of Problem-Based Learning 5(2), 37-69 (2011). doi: 10.7771/1541-5015.1254

J Griffin, E Kaplan, Q Burke, in Paper Presented at the IEEE 2nd Integrated STEM Education Conference, ISEC 2012. Debug'ems and other deconstruction kits for STEM learning (NJ, Ewing, 2012, March 9). doi: 10.1109/ISECon.2012.6204168

HW Hertzberg, Foundations. The 1892 Committee of ten. Soc. Educ. 52(2) (1988)

B Hindle, Emulation and Invention (W.W. Norton \& Company, New York, NY, 1981)

C Hmelo-Silver, Problem-based learning: What and how do students learn? Educ. Psychol. Rev. 16(3), 235-266 (2004). doi: 10.1023/B:EDPR.0000034022.16470.f3

M Holm, Project-based instruction: A review of the literature on effectiveness in prekindergarten through 12th grade classrooms. InSight: Rivier Academic. Journal 7(2), 1-13 (2011)

U Johansson-sköldberg, J Woodilla, Design thinking: Past, present and possible futures. Creativity and Innovation Management 22(2), 121-146 (2013). doi: 10.1111/caim.12023

$\mathrm{DH}$ Jonassen, Instructional design models for well-structured and ill-structured problem-solving learning outcomes. Educ. Technol. Res. Dev. 45(1), 65-90 (1997). doi: 10.1007/BF02299613

L Katehi, G Pearson, M Feder, The status and nature of K-12 engineering education in the United States. The Bridge 39(3), 5-10 (2009)

JS Krajcik, PC Blumenfeld, RW Marx, E Soloway, A collaborative model for helping middle grade science teachers learn instruction. Elem. Sch. J. 94(5), 482-497 (1994) Retrieved from http://www.jstor.org/stable/1001838

JS Krajcik, N Shin, in The Cambridge Handbook of the Learning Sciences, 2nd edn., ed. by R K Sawyer. Project-based learning (Cambridge University Press, New York, NY, 2014), pp. 275-297

$\mathrm{L}$ Martin, The promise of the maker movement for education. Journal of Pre-College Engineering Education Research 5(1), 30-39 (2015). doi: 10.7771/2157-9288.1099

RW Marx, PC Blumenfeld, JS Krajcik, E Soloway, Enacting project-based science. Elem. Sch. J. $97(4), 341$ (1997). doi: 10.1086/461870

S McMaster, The Telecommunications Industry: Emerging Industries in the United States, 1st edn. (Greenwood Press, Westport, CN, 2002)

Meister, M. (1922) The educational value of certain after-school materials and activities in science. (doctoral dissertation). Columbia University: New York.

JR Mergendoller, T Markham, J Ravitz, J Larmer, in Handbook of Classroom Management: Research, Practice, and Contemporary Issues, ed. by C M Evertson, C S Weinstein. Pervasive management of project based learning: Teachers as guides and facilitators (Lawrence Erlbaum, Inc., Mahwah, NJ, 2006)

J Morrison, AR Mcduffie, B French, Identifying key components of teaching and learning in a STEM school. Sch. Sci. Math. 115(5), 244-255 (2014). doi: 10.1111/ssm.12126

$S$ Morse, Experiments with one hundred pairs of Grove's battery, passing through one hundred and sixty miles of insulated wire. Am. J. Sci. 45, 390-394 (1845)

S Morse, The electromagnetic telegraph. Shaffner's Telegraph Companion 2, 1-96 (1855) 
Rattner, S. (2017). Made in America: The Bad News and the Good Bad News. New York Times. Retrieved from https://nyti.ms/2trfkfB

CM Reigeluth, in Instructional-design theories and models: A new paradigm of instructional theory, ed. by C M Reigeluth. The elaboration theory: Guidance for scope and sequence decisions, vol II (Lawrence Erlbaum associates, Mahwah, NJ, 1999), pp. 425-453

V Smil, Creating the twentieth century: Technical innovations of 1867-1914 and their lasting impact (Oxford University Press, New York, NY, 2005)

D Strumsky, J Lobo, S Van der Leeuw, Using patent technology codes to study technological change. Econ. Innov. New Technol. 21(3), 267-286 (2015)

The Boston Consulting Group. (2013). Developing an advanced manufacturing workforce for Virginia. Retrieved from https://www.revitalizeva.org/wp-content/uploads/2017/05/Strategic-Plan-2016.pdf

The Next Generation Science Standards: Executive Summary. (2013). Next Generation Science Standards. Retrived from The Next Generation Science Standards: Executive Summary" (PDF). Next Generation Science Standards. June 2013

JW Thomas, A Review of Research on Project-Based Learning (Autodesk Foundation, San Rafael, CA, 2000)

E Tulving, FIM Craik, The Oxford Handbook of Memory (Oxford University Press, Oxford, UK, 2000)

U.S. Department of Education, Science (Education for Global Leadership, Technology, Engineering and Math, 2015) Retrieved from https://www.ed.gov/stem

P Van Deur, R Murray-Harvey, The inquiry nature of primary schools and students' self-directed learning knowledge. Int Educ. J. 5(5), 166-177 (2005)

JJG van Merrienboer, PA Kirschner, L Kester, Taking the load off a learner's mind: Instructional design for complex learning. Educ. Psychol. 38(1), 5-13 (2003). doi: 10.1207/S15326985EP3801_2

Wells, J., \& Ernst, J. (2015). Integrative STEM Education. Retrieved from Virginia Tech School of Education website: http://www.soe.vt.edu/istemed/

White House, United States Government. (2014). A nation of makers. Retrieved from https://obamawhitehouse.archives. gov/nation-of-makers

Submit your manuscript to a SpringerOpen ${ }^{\circ}$ journal and benefit from:

- Convenient online submission

- Rigorous peer review

Open access: articles freely available online

High visibility within the field

Retaining the copyright to your article

Submit your next manuscript at $>$ springeropen.com 